\title{
Differential Effects of Cerebellar, Amygdalar, and Hippocampal Lesions on Classical Eyeblink Conditioning in Rats
}

\author{
Taekwan Lee ${ }^{1}$ and Jeansok J. Kim ${ }^{2}$ \\ ${ }^{1}$ Department of Psychology, Yale University, New Haven, Connecticut 06520-8205, and 2Department of Psychology and Program in Neurobiology and \\ Behavior, University of Washington, Seattle, Washington 98195-1525
}

\begin{abstract}
Eyeblink conditioning has been hypothesized to engage two successive stages of nonspecific emotional (fear) and specific musculature (eyelid) learning, during which the nonspecific component influences the acquisition of the specific component. Here we test this notion by investigating the relative contributions of the cerebellum, the amygdala, and the hippocampus to the emergence of conditioned eyelid and fear responses during delay eyeblink conditioning in freely moving rats. Periorbital electromyography (EMG) and $22 \mathrm{kHz} u l t r a s o n i c$ vocalization (USV) activities were measured concurrently from the same subjects and served as indices of conditioned eyeblink and fear responses, respectively. In control animals, conditioned EMG responses increased across training sessions, whereas USV responses were initially robust but decreased across training sessions. Animals with electrolytic lesions to their cerebellum (targeting the interpositus nucleus) were completely unable to acquire conditioned EMG responses but exhibited normal USV behavior, whereas animals with lesions to the amygdala showed decelerated acquisition of conditioned EMG responses and displayed practically no USV behavior. In contrast, hippocampal lesioned rats demonstrated facilitated acquisition of conditioned EMG responses, whereas the USV behavior was unaffected. The amygdalar involvement in eyeblink conditioning was examined further by applying the $\mathrm{GABA}_{\mathrm{A}}$ agonist muscimol directly into the amygdala either before or immediately after training sessions. Although pretraining muscimol infusions impaired conditioned EMG responses, post-training infusions did not. Together, these results suggest that, even during a simple delay eyeblink conditioning, animals learn about different aspects associated with the behavioral task that are subserved by multiple brain-memory systems that interact to produce the overall behavior.
\end{abstract}

Key words: amygdala; cerebellum; conditioned; fear; hippocampus; learning; memory

\section{Introduction}

Pavlovian or classical eyeblink conditioning is widely used as a model system to understand the mammalian brain mechanisms underlying learning and memory (Thompson, 1986, 1990; Yeo, 1991; Raymond et al., 1996; Medina et al., 2002). Behavioral studies from various animals, including rats, mice, humans, and particularly rabbits, have shown that eyeblink conditioning occurs when an initially innocuous conditioned stimulus (CS) (such as tone or light) is contingently paired with an aversive unconditioned stimulus (US) (such as air puff or electric shock to the eye region) that produces a reflexive eyeblink [unconditioned response (UR)]. Through CS-US association formation, the CS becomes capable of eliciting a learned eyeblink [conditioned response (CR)] that is closely time locked to the onset of the US (Schneiderman et al., 1962; Thomas and Wagner, 1964).

Received Dec. 5, 2003; revised Feb. 13, 2004; accepted Feb. 17, 2004.

This work was supported by grants from the Whitehall Foundation and the National Institute of Mental Health (MH64457) to J.J.K. We thank Allan R. Wagner, Karyn M. Frick, and June-Seek Choi for invaluable comments on this manuscript.

Correspondence should be addressed to Jeansok J. Kim, Department of Psychology, Guthrie Hall, Box 351525, University of Washington, Seattle, WA 98195-1525. E-mail: jeansokk@u.washington.edu.

D0I:10.1523/JNEUROSC1.5382-03.2004

Copyright $\odot 2004$ Society for Neuroscience $\quad$ 0270-6474/04/243242-09\$15.00/0
Among associative tasks, eyeblink conditioning is particularly amenable to neurobiological analyses because (1) it involves only two stimuli, where the onset and offset of CS and US can be precisely controlled, (2) the CR and UR are discrete behavioral units that can be accurately and repetitively measured within and between training sessions, and (3) the CR and UR are anatomically and behaviorally dissociable. Converging evidence from lesion, pharmacological, recording, stimulation, brain imaging, and genetic engineering studies indicate that the cerebellum is essential for eyeblink conditioning (Kim and Thompson, 1997; Medina et al., 2002).

Although most eyeblink conditioning studies focus exclusively on the motor output of interest (i.e., eyeblink), it has been recognized that animals also learn about emotional aspects associated with the task (Lavond et al., 1993). Contrary to eyeblink CRs, which typically emerge after numerous CS-US pairings, fear responses (e.g., alterations in heart rate, blood pressure, pupillary dilation) are observed after only a few CS-US pairings. The developments of nonspecific emotional and specific motor responses are referred to as the first phase and the second phase, respectively, of two-process models of conditioning (Konorski, 1967; Rescorla and Solomon, 1967). It has been postulated that nonspecific emotional responses facilitate the subsequent acqui- 
sition of specific motor responses (Lennartz and Weinberger, 1992; Mintz and Wang-Ninio, 2001). In support, lesions to the amygdala, which abolish fear conditioning (Blanchard and Blanchard, 1972; Kim et al., 1993; LeDoux, 2000), reduce the CSinduced reflex facilitation of eyeblink UR and retard the acquisition of eyeblink CR in rabbits (Weisz et al., 1992). Additionally, rats that first underwent fear conditioning subsequently displayed facilitated motor conditioning (Neufeld and Mintz, 2001). Thus, during eyeblink conditioning, animals exhibit both eyeblink and fear responses, during which the latter seems to influence the acquisition of the former.

The present study explored further the two-process models of conditioning by investigating cerebellar and amygdalar lesion effects on eyeblink and fear responses concurrently during delay eyeblink conditioning in rats. Hippocampal lesion effects were also examined because although this structure is not necessary (Schmaltz and Theios, 1972; Kim et al., 1995), its neurons become engaged during delay eyeblink conditioning (Berger et al., 1976; Weisz et al., 1984; Disterhoft et al., 1986), which might influence conditioning (Kim and Baxter, 2001).

\section{Materials and Methods}

Experiment 1: emergence of nonspecific fear and specific motor responses during delay eyeblink conditioning

Results from previous rabbit studies have shown that during delay eyeblink conditioning, animals initially display nonspecific fear responses subsequently followed by discrete eyeblink musculature responses, which are consistent with two-process models of conditioning (Lavond et al., 1993). The goal of experiment 1 was to determine whether unrestrained, freely moving rats also demonstrate two-process-like learning during delay eyeblink conditioning, using $22 \mathrm{kHz}$ ultrasonic vocalization (USV) and periorbital electromyography (EMG) as indices of fear and musculature responses, respectively. Although USV and periorbital EMG measures have been widely used in fear conditioning and eyeblink conditioning studies, respectively, in rodents (Shors et al., 1989; Blanchard et al., 1991; Chen et al., 1996; Weiss et al., 1999; Lee et al., 2001; Miyata et al., 2001; Choi and Brown, 2003), the present study is the first to concurrently assess both responses during eyeblink conditioning.

Subjects. Experimentally naive male Sprague Dawley rats (Charles River, Kingston, NY), initially weighing 275-300 gm, were housed individually in a climate-controlled vivarium on a $12 \mathrm{hr}$ light/dark cycle with ad libitum access to food and water. All experiments were conducted during the light phase of the cycle, and all surgical, postoperative care, and behavioral procedures were performed in strict compliance with the Yale Animal Resource Center guidelines.

Surgery. Rats were anesthetized via intraperitoneal injection of a 30 $\mathrm{mg} / \mathrm{kg}$ ketamine and $2.5 \mathrm{mg} / \mathrm{kg}$ xylazine mixture (with supplemental injections given as needed) and placed on a stereotaxic instrument with nonpuncture ear bars (Stoelting, Wood Dale, IL). The scalp was incised and small burr holes were drilled for anchoring screws on the skull. Afterward, animals were implanted subcutaneously with four Tefloncoated stainless steel wires (0.003 inch bare, 0.0045 inch coated; A-M Systems, Everett, WA) in the left upper eyelid. The tip of the wire was exposed $(\sim 1.0 \mathrm{~mm})$, bent to a $\mathrm{V}$-shape, and hooked to obicularis oculi muscles (Basso et al., 1993). Two of the four wires were used to record differential EMG, and the remaining two wires were used to deliver periorbital shock. The other ends of the wires, along with a ground wire attached to one of the anchoring screws, were soldered to gold-plated pins of an Augat socket (TYCO Electronics, Harrisburg, PA), which was then cemented to the animal's skull. After surgery, all animals were given $6 \mathrm{~d}$ of postoperative recovery and were adapted to handling for $2 \mathrm{~d}$ before training.

Apparatus. Eyeblink conditioning took place in two modular operant test chambers $(27 \mathrm{~cm}$ width $\times 28 \mathrm{~cm}$ length $\times 30.5 \mathrm{~cm}$ height; Coulbourn Instruments, Allentown, PA), each placed inside a soundattenuating chest (Med Associates, St. Albans, VT) and a Faraday field. The floor grid (composed of 16 stainless steel bars) and base pan of each chamber were washed thoroughly with tap water and dried completely before placing each animal in the chamber.

The stimulus presentations were controlled, and EMG-USV data were simultaneously collected by an IBM-PC Pentium III computer equipped with a data acquisition board (PCI-MIO-16E-1; National Instruments, Austin, TX) via a custom-written software (LabVIEW; National Instruments). The tone CS ( $2.8 \mathrm{kHz}$ sine wave, $82 \mathrm{~dB}$ ) was produced using a function generator (4040A; BK Precision, Yorba Linda, CA) and presented through a speaker mounted on the chamber. The periorbital shock US (50 Hz, square wave pulses) was delivered using a stimulus isolator (SD9; Grass Telefactor, West Warwick, RI). The US intensity was adjusted daily for each animal to a minimal voltage to elicit a reliable eyeblink response (Skelton, 1988; Chen et al., 1996). The EMG activity from the eyelid muscle was amplified $(1000 \times)$ and filtered $(300-5000$ $\mathrm{Hz}$ ) through a differential AC amplifier (model 1700; A-M Systems), digitized (sampling rate $=10 \mathrm{kHz}$ ), and stored to a computer. To prevent US-induced saturation of the amplifier, the EMG input to the amplifier was "disconnected" from $5 \mathrm{msec}$ before and after the US with a clamping device (model 2804; Cambridge Electronics Design, Cambridge, UK). The animal's head socket was connected to a ceiling-mounted cablecommutator assembly (CAY-675-12 slip ring; Airflyte Electronics, Bayonne, NJ) that relayed EMG signals and delivered the US in a freely moving rat.

For USV data collection, a Mini-3 bat detector (Noldus Information Technology, Wageningen, The Netherlands) was used to transform highfrequency $(22 \pm 5 \mathrm{kHz})$ sounds into the audible range $(300-3000 \mathrm{~Hz})$. The transformed output from the bat detector was digitized (sampling rate $=1 \mathrm{kHz}$ ) and stored to the computer. Both EMG and USV activities around the time of CS-US presentations and USV activities during the intertrial interval (ITI) were monitored and stored for off-line analysis (see below).

Training procedure. A day before training, each rat was placed in the eyeblink chamber, with its headstage connected to a cable-commutator assembly, for $60 \mathrm{~min}$ of habituation to the training environment.

On all days of training, animals were presented with a $400 \mathrm{msec}$ tone CS and a coterminating $100 \mathrm{msec}$ shock US pairing [delay paradigm with $300 \mathrm{msec}$ inter-stimulus interval (ISI)]. Animals received six daily sessions of training; each session consisted of 100 trials arranged into 10 blocks, and each block included 1 CS-alone test trial and 9 CS-US paired trials. The trials were delivered every $20-40 \mathrm{sec}$ (mean ITI $30 \mathrm{sec}$ ).

Data analysis. Eyeblink analysis was on the basis of raw EMG signals (EMG recording starts at $350 \mathrm{msec}$ before the CS onset and continues until $600 \mathrm{msec}$ after the US offset totaling $1350 \mathrm{msec}$ of sampling) of each trial. Root mean square (RMS) for every $1 \mathrm{msec}$ period was calculated out of 10 sampling points

$$
\mathrm{RMS}=\sqrt{\frac{1}{10} \sum_{i=1}^{10} x_{i}^{2}}
$$

( $x$ indicates $0.1 \mathrm{msec}$ raw EMG value) of each trial. To determine CR and UR for each trial, four time windows were defined as follows: (1) pre-CS period: $350 \mathrm{msec}$ baseline period before CS onset; (2) startle period: 80 msec period after CS onset; (3) CS period: 215 msec period from the offset of startle period to $5 \mathrm{msec}$ before US onset (for CS-US paired trials), or $520 \mathrm{msec}$ period from the offset of startle period to $200 \mathrm{msec}$ after CS termination (for CS-alone trials); and (4) post-US period: 595 msec period after US termination (Fig. 1). As mentioned previously, EMG was not recorded from the period between $5 \mathrm{msec}$ before and after US because a clamping device disconnected the amplifier from signal as well as US-induced artifact.

Trials with either unstable baseline EMG activity during the pre-CS period or tone-induced startle EMG activity (immediately after the CS) were excluded from analysis (Chen et al., 1996). An unstable baseline trial was defined as a trial with three consecutive RMS values of pre-CS period $>0.1 \mathrm{mV}$. A startle trial was defined as a trial with three consecutive RMS values during the startle period higher than mean +4 SDs of the pre-CS period. For the remaining valid trials, the $\mathrm{CR}$ was defined as a trial containing three consecutive RMS values of CS period higher than mean +4 

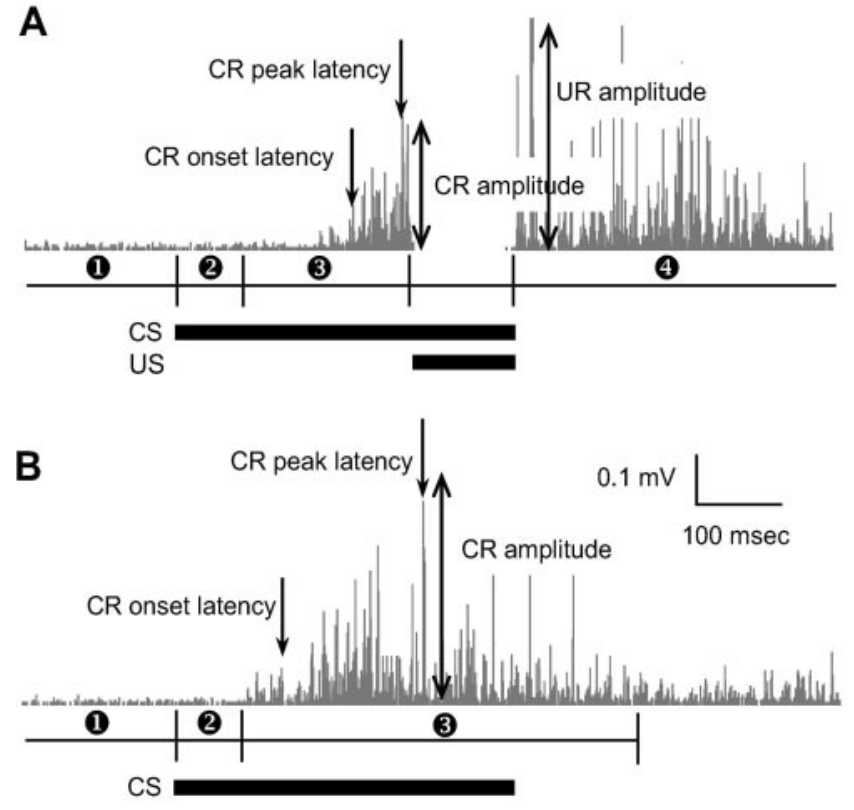

Figure 1. Conditioned EMG analysis. A, Rectified raw EMG signals during a CS-US paired trial and four time windows corresponding to (1) Pre-CS, (2) startle, (3) CS, and (4) post-US periods. $B$, Rectified raw EMG signals during a (S-alone trial and three time windows representing (1) Pre-CS, (2) startle, and (3) CS periods. Horizontal black bars indicate CS and US onset- offset.

SDs of the pre-CS. The percentage of CR was computed as the ratio of the number of CRs to the number of valid trials. The CR onset latency was calculated from the first moment when three RMS values exceeded the mean +4 SDs of the pre-CS. During the CS period, the maximum RMS value was considered the maximum CR amplitude, and the moment of maximum RMS value was defined as the peak CR latency. The residual UR amplitude was defined as the maximum RMS value during the post-US period.

The duration of USV was computed from USV data collected throughout the entire training session. The parameters for USV analysis were on the basis of the analysis of Brudzynski et al. (1993). A USV call was defined as an uninterrupted sound at least $300 \mathrm{msec}$ in length. If the interval between two calls was $<50 \mathrm{msec}$, then the two calls were combined to a single call. Custom programs written in LabVIEW were used to analyze and display raw EMG and USV data.

Experiment 2: effects of interpositus nucleus, amygdala, and hippocampus lesions on eyeblink and fear responses

Experiment 1 demonstrated that nonspecific fear and specific eyelid musculature responses occur during delay eyeblink conditioning in rats. Because the amygdala is implicated in fear conditioning (Blanchard and Blanchard, 1972; Kapp et al., 1979; Davis, 1992; Kim et al., 1993; Fanselow and LeDoux, 1999; LeDoux, 2000) whereas the cerebellum (i.e., the interpositus nucleus) is essential for eyeblink conditioning (Thompson, 1986, 1990; Yeo, 1991; Kim and Thompson, 1997; Medina et al., 2002), the purpose of experiment 2 was to examine amygdalar and interpositus nucleus lesion effects on the development of conditioned EMG and USV responses. In addition, hippocampal lesion effects were investigated because neurons in the hippocampus undergo learningrelated changes during delay eyeblink conditioning (Berger et al., 1976; Weisz et al., 1984; Disterhoft et al., 1986) that can potentially influence eyeblink and USV responses.

Subjects, surgeries, and behavioral training. Naive Sprague Dawley male rats were randomly assigned to one of four groups: sham lesion control (CONT), interpositus nucleus lesion (IP), amygdala lesion (AMYG), and hippocampal lesion (HIPP). Bilateral electrolytic lesions were made by passing constant current (UGO Basile, 3500 Lesion Making Device, Comerio, Italy) through a stainless steel insect pin (\#00) insulated with epoxylite except for $0.5-0.75 \mathrm{~mm}$ at the tip. The following coordinates
(Paxinos and Watson, 1997) and lesion parameters were used: interpositus nucleus (from bregma, $-11.3 \mathrm{~mm}$ posterior, \pm 1.8 and $\pm 2.6 \mathrm{~mm}$ lateral, and $-6.5 \mathrm{~mm}$ ventral; current: $1 \mathrm{~mA}, 10 \mathrm{sec}$ ); amygdala (from bregma, $-2.3 \mathrm{~mm}$ posterior, \pm 4.0 lateral and $-8.4 \mathrm{~mm}$ ventral, \pm 5.0 $\mathrm{mm}$ lateral and $-8.8 \mathrm{~mm}$ ventral; current: $1 \mathrm{~mA}, 10 \mathrm{sec}$ ); dorsal hippocampus (from bregma, $-2.6 \mathrm{~mm}$ posterior, \pm 1.0 and $\pm 2.0 \mathrm{~mm}$ lateral, $-4.0 \mathrm{~mm}$ ventral, and $-4.0 \mathrm{~mm}$ posterior, \pm 2.2 and $\pm 3.5 \mathrm{~mm}$ lateral, $-4.0 \mathrm{~mm}$ ventral; current: $1 \mathrm{~mA}, 15 \mathrm{sec}$ ). For sham controls, the electrode was lowered $1 \mathrm{~mm}$ just dorsal to the lesion sites without passing current. Next, animals received EMG electrode implant and head socket cementing in the same manner as in experiment 1. After surgery, animals underwent recovery and handling as described previously.

During training, animals were presented with $350 \mathrm{msec}$ tone CS and $100 \mathrm{msec}$ shock US pairings (delay paradigm with a $250 \mathrm{msec}$ ISI). Control and hippocampal lesion groups underwent six daily sessions of training, whereas interpositus nucleus and amygdala lesion groups received three additional daily sessions of training (for a total of nine sessions) to assess lesion effects more comprehensively. Each session consisted of 60 trials arranged into 6 blocks, and each block included 1 CS-alone test trial and 9 CS-US paired trials. The ITI was $40-60 \mathrm{sec}$ (mean $50 \mathrm{sec}$ ). Experiment 2 used $350 \mathrm{msec}$ tone CS, $50 \mathrm{sec}$ ITI, and 60 trials per session (instead of $400 \mathrm{msec}$ tone CS, $30 \mathrm{sec}$ ITI, and 100 trials per session in experiment 1 ) because lengthening the ITI/ISI ratio facilitated the development of eyeblink CR, which compensated for the reduction in the number of CS-US paired presentations.

Behavioral analyses were performed as described in experiment 1 with minor changes to accommodate the different CS duration and ISI used. The duration of the pre-CS period and startle period were the same; however, the CS period and post-US period were now as follow: (1) CS period: $165 \mathrm{msec}$ period from the offset of startle period to $5 \mathrm{msec}$ before US onset (in CS-US paired trials), and $470 \mathrm{msec}$ period from the offset of startle period to $300 \mathrm{msec}$ after CS termination (in CS-alone trials), and (2) post US period: $645 \mathrm{msec}$ period after US termination.

Histology. At the completion of behavioral testing, the subjects were overdosed with ketamine $\mathrm{HCl}$ and xylazine and perfused intracardially with $0.9 \%$ saline followed by $10 \%$ buffered formalin. The brains were removed and stored in $10 \%$ formalin for at least 2 weeks and then stored in $30 \%$ sucrose solution for $24 \mathrm{hr}$ before being sliced. Transverse sections $(50 \mu \mathrm{m})$ were taken through the extent of the lesion site, mounted on gelatinized slides, and stained with Prussian Blue and cresyl violet dyes. The full extent of each lesion site was examined microscopically, and subjects with inaccurate lesion placements were excluded from the statistical analysis.

\section{Experiment 3: effects of reversible inactivation of amygdala on eyeblink and fear responses}

Experiment 2 indicated that amygdalar lesions retard the acquisition of conditioned EMG responses and abolish the fear-induced USV behavior. Because electrolytic lesions damage both cells and fibers of passage, however, it is unclear whether the amygdalar lesion effects on conditioned EMG and USV responses were caused by damaging intrinsic amygdalar neurons or fibers that course through the amygdala. Thus, the present study used the $\mathrm{GABA}_{\mathrm{A}}$ receptor agonist muscimol to pharmacologically inactivate amygdalar neurons during eyeblink conditioning. Additionally, because several studies have reported that immediate post-training inactivations of the amygdala can impair memory consolidation processes in other brain-memory systems (McGaugh, 2002), we also examined whether muscimol infusions immediately after eyeblink training sessions can influence the development of eyeblink CRs.

Subjects and surgeries. Naive Sprague Dawley male rats were implanted with 26 gauge guide cannulas (Plastic One, Roanoke, VA) bilaterally into the basolateral nucleus of the amygdala (from bregma: $-2.3 \mathrm{~mm}$ posterior, $\pm 5 \mathrm{~mm}$ lateral, $-7.7-8.0 \mathrm{~mm}$ ventral). Implanted cannulas were cemented to four anchoring screws on the skull. Dummy cannulas were inserted into the implanted cannulas to maintain patency of the guide cannulas. Next, animals underwent EMG electrode implant and head socket cementing in the manner described in experiment 1. During 5-7 d of postoperative recovery, the rats were adapted to handling, and each dummy cannula was removed and replaced with a clean one. 


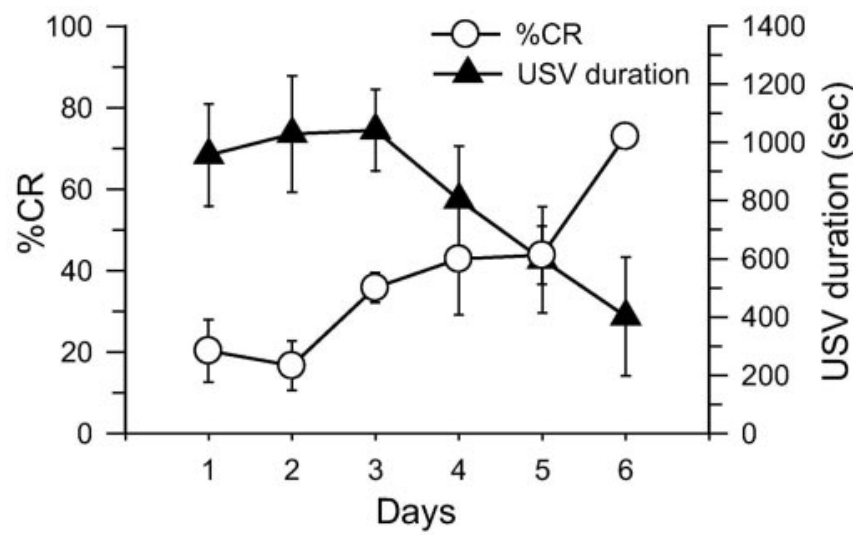

Figure 2. Mean percentage of conditioned EMG ( \pm SE) and mean USV duration ( \pm SE) measured from unoperated rats $(n=6)$ during the six daily training sessions.

Drugs and behavioral training. Muscimol free-base (Sigma-Aldrich, St. Louis, MO), dissolved in artificial CSF (ACSF) (10 mM, pH 7.4) was microinfused into the amygdala (bilaterally) by backloading the drug up a 33 gauge internal cannula into polyethylene (PE 20) tubing connected to $10 \mu \mathrm{l}$ Hamilton microsyringes (Hamilton Company, Reno, NV). The internal cannula protruded $1 \mathrm{~mm}$ beyond the guide cannula. An infusion volume of $0.3 \mu \mathrm{l}$ (per side) was delivered using a Harvard PHD2000 syringe pump (Harvard Apparatus, South Natick, MA) over the course of $3 \mathrm{~min}$ (at a rate of $0.1 \mu \mathrm{l} / \mathrm{min}$ ). The internal cannula remained in place for at least $30 \mathrm{sec}$ after the infusions before being pulled out.

Animals were randomly assigned to one of four groups: ACSF infusions before training days 1-3 (CONT); muscimol infusions before training days 1-3 (pretraining MUSC); muscimol infusions immediately after training days 1-3 (post-training MUSC); and muscimol infusions before training days 5-7 (preretention MUSC). Approximately $10 \mathrm{~min}$ after ACSF or MUSC infusions, pretraining and preretention groups underwent eyeblink training in the same manner as in experiment 2 . The post-training MUSC animals received muscimol infusions immediately after undergoing eyeblink training. Behavioral analyses were performed as described in experiment 2 .

Histology. At the completion of behavioral testing, the subjects' brains were removed and stored in the same manner as in experiment 2. Transverse sections $(50 \mu \mathrm{m})$ were taken through the extent of the cannula placement, mounted on gelatinized slides, and stained with cresyl violet dye. An observer unaware of the behavioral data determined the locations of the cannula tips, and subjects with inaccurate cannula placements were excluded from the statistical analysis.

\section{Results}

\section{Experiment 1}

Figure 2 shows the mean percentage of conditioned EMG and the mean USV duration across $6 \mathrm{~d}$ of training in unrestrained, freely moving rats. As can be seen, conditioned EMG responses gradually increased across training sessions, whereas USV responses were initially robust but declined across training sessions. These observations are supported by a linear trend analysis, (eyeblink CR\%: $F_{(1,30)}=29.89, p<0.01$; USV duration: $F_{(1,30)}=7.97, p<$ .01 ), and are thus consistent with two-process models of conditioning (Konorski, 1967; Rescorla and Solomon, 1967).

\section{Experiment 2}

Figure 3 represents composites of cerebellar, amygdalar, and hippocampal lesions on the basis of a reconstruction of lesion extents (Paxinos and Watson, 1997). Cerebellar lesions included the anterior interpositus nucleus, portions of the overlying cerebellar cortex, and adjacent dentate nucleus and medial fastigial nucleus. Amygdalar-lesioned brains had damage to lateral, basolateral, and central nuclei of the amygdala and small portions of overlying striatum. Brains with hippocampal lesions had damage to the dorsal hippocampus and overlying cortex.

Figure $4 A$ displays the mean CR percentages from CONT $(n=12)$, IP $(n=9)$, AMYG $(n=9)$, and HIPP $(n=10)$ lesion animals. A two-way ANOVA with the first six daily sessions of training as a repeated measure indicates significant main effects of group $\left(F_{(3,36)}=25.35 ; p<0.01\right)$ and day $\left(F_{(5,180)}=27.36 ; p<\right.$ $0.01)$, and a significant group $\times$ day interaction $\left(F_{(15,180)}=4.24\right.$; $p<0.01)$. Newman-Keuls post hoc tests reveal that the HIPP lesion group showed a significantly higher CR percentage than the control group, whereas interpositus and amygdala lesion groups displayed significantly lower CR percentages than controls (all $p<0.05$ ). Further analyses comparing CR percentages from the last day of training (day 6 for CONT and HIPP groups, day 9 for AMYG and IP groups) indicate a significant group difference (one-way ANOVA; $F_{(3,36)}=15.09 ; p<0.01$ ). Specifically, IP lesion animals displayed a significantly lower CR percentage than other groups (all $p<0.05$; Newman-Keuls).

Analyses of the CR amplitude (Fig. $4 B$ ) produced results similar to the CR percentage (main effects of group: $F_{(3,36)}=5.05$, $p<0.01$; days: $F_{(5,180)}=10.18, p<0.01$; group $\times$ day interaction: $\left.F_{(15,180)}=2.34, p<0.01\right)$. As can be seen, the CR amplitudes increased over training days for all groups except for the IP lesion group, and HIPP animals exhibited significantly larger CR amplitudes compared with other groups during the first 6 training days $(p<0.05)$. Interestingly, although the AMYG lesion animals acquired the CR percentages slower than the CONT animals (Fig. $4 A$ ), the mean CR amplitudes during $6 \mathrm{~d}$ of training were similar between the two groups (Fig. $4 B)(p>0.05)$. This finding suggests that the relatively sparse CRs displayed by AMYG animals during the first $6 \mathrm{~d}$ of training are just as robust as the relatively frequent CRs displayed by CONT animals.

The temporal characteristics of the CRs were compared among CONT, AMYG, and HIPP groups by analyzing the CR onset latencies (Fig. 4C) and the CR peak latencies (Fig. 4D) on the last day of training. The IP lesion animals were excluded because they did not exhibit CRs. A one-way ANOVA indicated significant group differences in the CR onset latency $\left(F_{(2,28)}=\right.$ 3.78; $p<0.05)$. Neither AMYG nor HIPP lesion animals reliably differed from CONT animals, but HIPP animals exhibited a significantly shorter CR onset latency than AMYG animals $(p<$ 0.05). Although the shorter CR onset latency of the hippocampal lesion animals is congruent with previous findings in rabbits (Port et al., 1985) and might reflect the disruption of temporal processing of stimuli, there were no reliable group differences in the CR peak latency (one-way ANOVA; $\left.F_{(2,28)}=1.02 ; p>0.05\right)$.

The mean USV duration for 6 training days was analyzed to compare the emotional response among the CONT, AMYG, IP, and HIPP groups (Fig. $4 E$ ). A one-way ANOVA indicates a significant group difference in the USV duration $\left(F_{(3,36)}=5.9 ; p<\right.$ 0.01 ). Subsequent post hoc tests revealed that the AMYG lesioned animals emitted significantly less USV compared with other groups (all $p<0.05$; Newman-Keuls). No differences in USV were observed among the CONT, IP, and HIPP groups $(p>$ $0.05)$. To better appreciate USV behavior both within a session and across training sessions, Figure 5 depicts sample USV patterns from typical animals in CONT, IP, and HIPP groups. As can be seen, USV responses decrease both as a function of trials within a session and as a function across training sessions. The mean USV call durations for 6 training days were not significantly different among groups (one-way ANOVA; $F_{(2,30)}=1.06 ; p>$ 
A

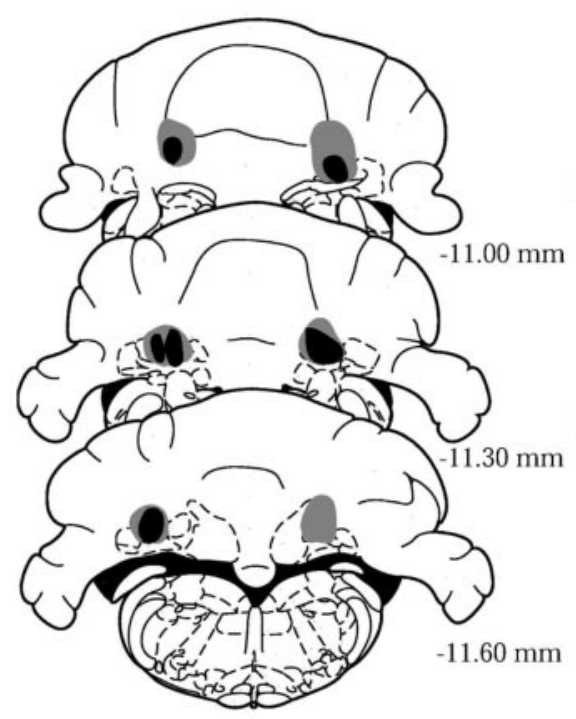

B

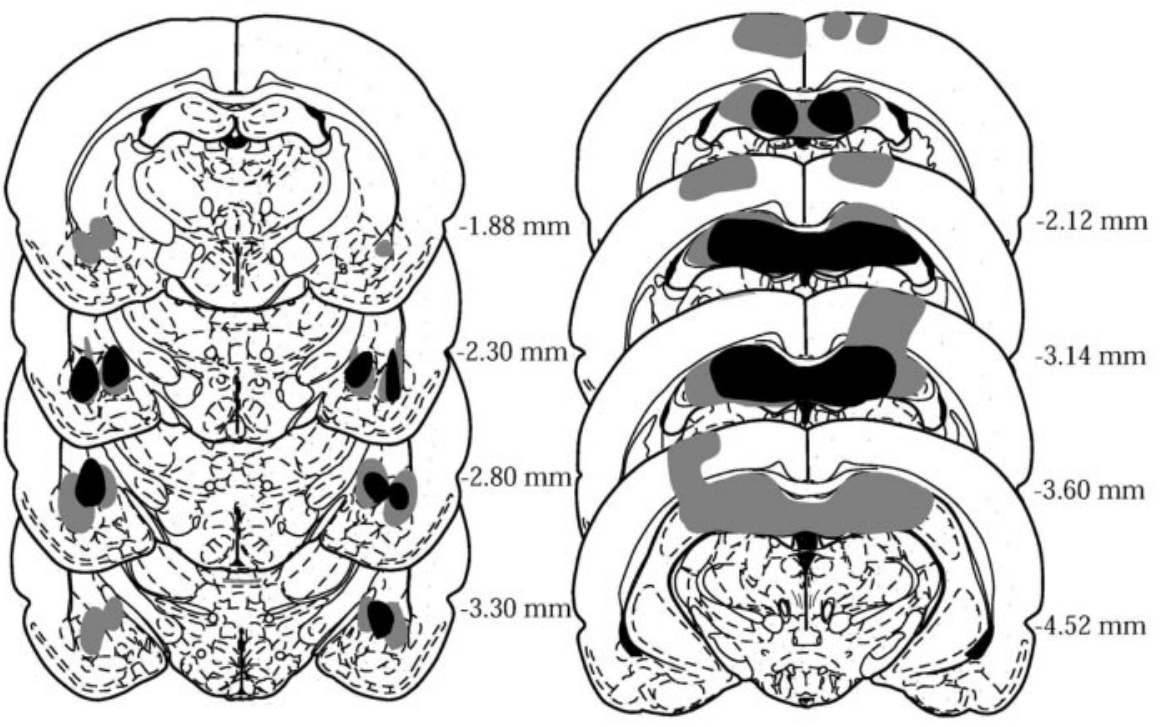

Figure 3. Histological reconstructions of lesion sites. Numbers indicate distance in millimeters posterior to the bregma. A, Interpositus nucleus lesions. B, Amygdala lesions. C, Hippocampus lesions. Gray areas represent the largest lesion, and black areas represent the smallest lesion on a given section.

0.05). It appears then interpositus nucleus and hippocampal lesions do not alter USV behavior (Fig. 5D).

To check for possible lesion effects on US sensitivity, which can contribute to differences in conditioned EMG and USV responses among groups, the ratio of residual UR amplitude to US intensity was computed. Although the UR/US ratio of amygdala lesion animals was smallest numerically, there were no reliable group differences (one-way ANOVA; $F_{(3,36)}<1$ ) (Fig. $4 F$ ).

\section{Experiment 3}

Figure $6 A$ depicts the mean percentage of conditioned EMG from CONT $(n=6)$, pretraining MUSC $(n=6)$, preretention MUSC $(n=6)$, and post-training MUSC $(n=5)$ groups. A two-way ANOVA with the first three daily training sessions as a repeated measure reveals significant main effects of group $\left(F_{(3,19)}=7.37 ; p<0.01\right)$, day $\left(F_{(2,38)}=21.44 ; p<0.01\right)$, and a significant group $\times$ day interaction $\left(F_{(6,38)}=\right.$ 4.07; $p<0.01$ ). Although the pretraining MUSC group did not develop conditioned EMG, the post-training MUSC group acquired CRs comparable with the CONT group (Newman-Keuls; $p<0.05$ ). As with conditioned EMG data, USV was impaired only in pretraining MUSC animals during the first three training sessions (Fig. 6B) (two-way ANOVA: $F_{(3,19)}=12.46, p<$ 0.01; Newman-Keuls: $p<0.05$ ). In contrast to conditioned EMG, there were no significant main effects in day
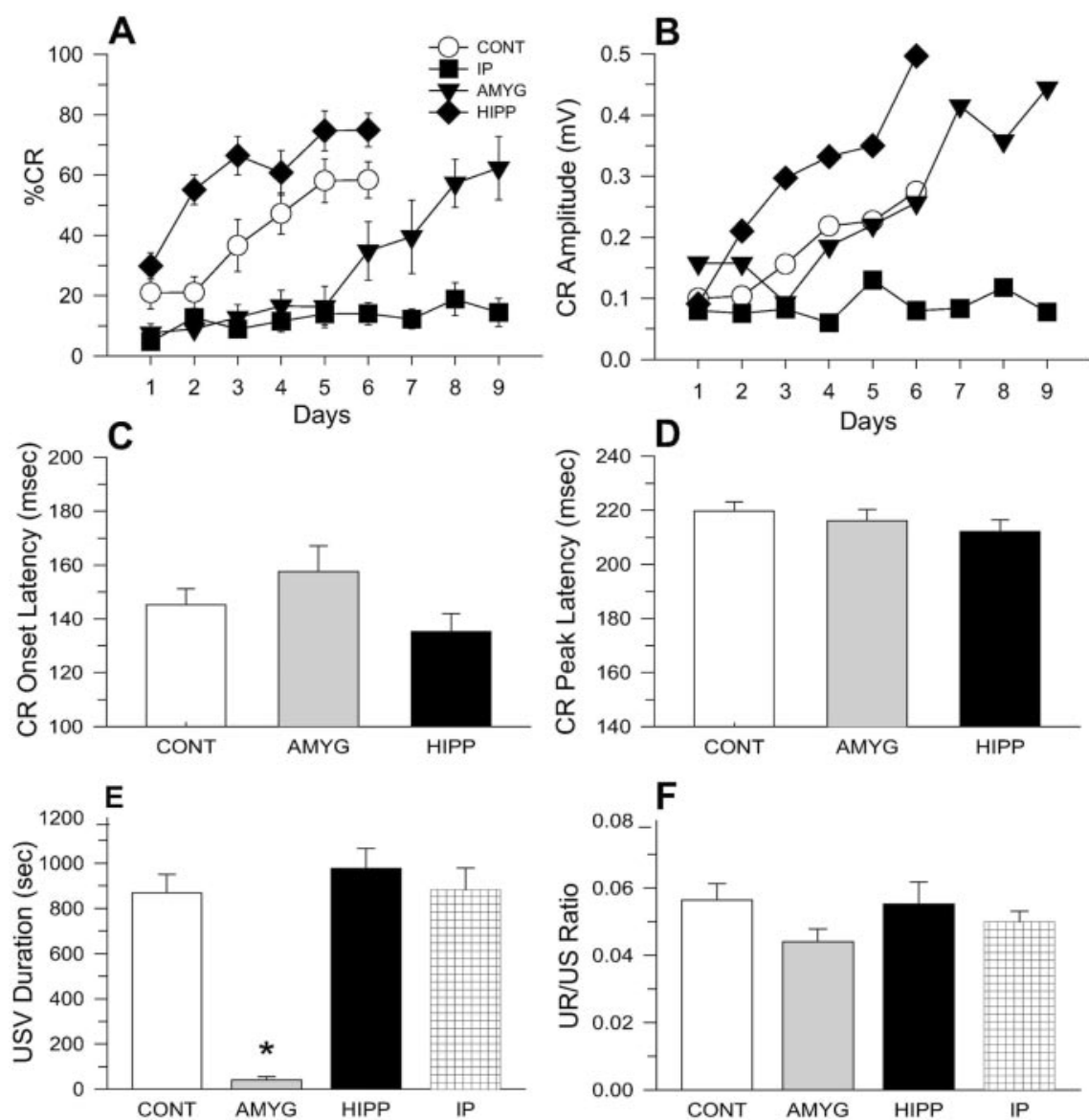

Figure 4. Lesion effects on eyeblink (Rs and USVs. $A$, Mean percentage of $C R( \pm S E)$ during daily training sessions from control (CONT: $\bigcirc, n=12$ ), interpositus nucleus lesion (IP: $\mathbf{\square}, n=9$ ), amygdala lesion (AMYG: $\mathbf{\nabla}, n=9$ ), and hippocampus lesion (HIPP: $\checkmark, n=10$ ) animals. $B$, Mean (R amplitude during $6 \mathrm{~d}$ of training session. C, Mean CR onset latency during the last day of training session. $D$, Mean CR peak latency during the last day of training session. $E$, Mean USV duration recorded during $6 \mathrm{~d}$ of the training session. $F$, Mean ratio of residual UR amplitude to US intensity. 

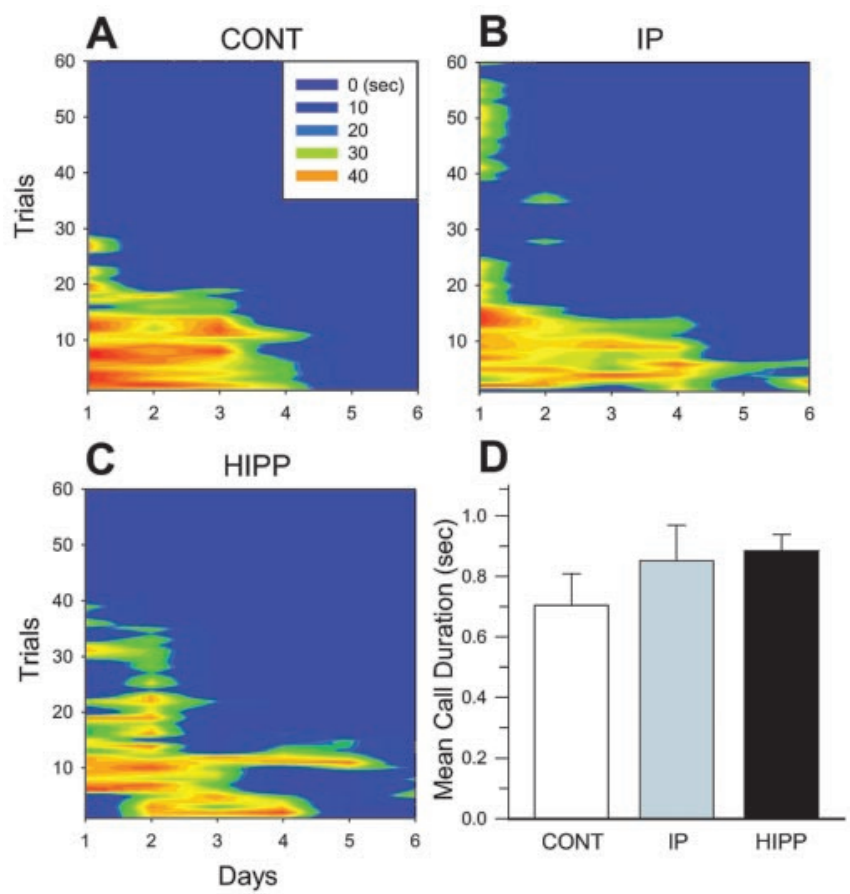

Figure 5. Examples of USV patterns emitted from a typical control $(A)$, interpositus nucleus $(B)$, and hippocampus ( $C$ lesion animals during eyeblink conditioning across trials and days. Colors represent the magnitudes of USV duration. D, Mean USV call durations during $6 \mathrm{~d}$ of training sessions ( $+S E)$. Those in the amygdala lesion group are not included because they did not emit USVs.

$\left(F_{(2,38)}=1.00 ; p>0.05\right)$ and group $\times$ day interaction $\left(F_{(6,38)}\right.$ $<1$ ). Thus, only pretraining muscimol infusion prevented the acquisition of CRs and expression of USV.

In Figure $6 C$, the mean CR percentage from days $4-9$ of the pretraining MUSC group was compared with those of CONT and post-training MUSC groups. The pretraining MUSC animals acquired CRs at a similar rate after withdrawal of muscimol infusions compared with other groups $\left(F_{(2,14)}=1.60 ; p>0.05\right)$.

To examine muscimol effects on animals that already acquired CRs (i.e., preretention MUSC group), CR percentages and USV were compared between muscimol infusion sessions (days 5, 6, and 7) and no infusion sessions (days 1, 2, 3, 4, 8, and 9) (Fig. $6 D)$. A $t$ test revealed that muscimol infusions into the amygdala on day 5 significantly reduced CR percentages and USV when compared with day 4 ( $\%$ CR: $t_{(10)}=2.98, p<0.05$; USV: $t_{(10)}=$ $2.78, p<0.05)$; however, the performance of eyeblink CRs and USV fully recovered in the eighth session in contrast to the seventh session (\%CR: $t_{(10)}=4.78, p<0.01$; USV: $t_{(10)}=3.95, p<$ 0.01 ). In short, animals that acquired eyeblink CRs $\sim 50 \%$ during four successive training sessions did not express learned CRs and USV during sessions of muscimol infusions but exhibited fully recovered CRs and USV after withdrawal of muscimol. Pretraining and preretention effects of muscimol cannot be accounted for by alterations in US sensitivity or UR, because the ratio of residual UR to US intensity did not differ between infusion and no infusion days (Fig. $6 E$ ). Figure $6 F$ shows a composite of the bilateral infusion sites in the basolateral amygdalar complex on the basis of a reconstruction of cannula placements (Paxinos and Watson, 1997).

In summary, inactivating the amygdala via muscimol infusions not only slowed the development of eyeblink CRs but also impaired the expression of learned CRs and abolished USV behavior.

\section{Discussion}

The results from the present study demonstrate that consistent with the two-process models of conditioning (Konorski, 1967; Rescorla and Solomon, 1967), rats exhibit two successive stages of nonspecific emotional (fear) and specific musculature (eyelid) learning during delay eyeblink conditioning. Whereas the USV responses (signifying fear) were initially robust and decreased across training sessions, the conditioned EMG responses (indicating eyeblink learning) were initially small and increased across training sessions (experiment 1). Moreover, lesions to the cerebellum, the amygdala, and the hippocampus produced dissimilar effects on conditioned eyeblink and USV responses (experiment 2). Specifically, cerebellar lesions (targeting the IP nucleus) effectively blocked the acquisition of eyeblink CRs without affecting fear-induced USV behavior, whereas amygdalar lesions impaired USV and slowed the acquisition of eyeblink CRs. Hippocampal lesioned animals, on the other hand, exhibited normal USV and facilitated acquisition of eyeblink CRs.

Similar to the amygdalar lesion effects, targeted infusions of the $\mathrm{GABA}_{\mathrm{A}}$ receptor agonist muscimol into the amygdala before training sessions blocked USV responses and slowed the acquisition of eyeblink CRs (experiment 3). In previously trained animals, pretesting infusions of muscimol impaired USV behavior and markedly reduced the expression of eyeblink CRs. As muscimol increases $\mathrm{Cl}^{-}$ion conductance across cell membranes (Feldman et al., 1997), presumably the drug effects are caused by inhibiting or reducing neuronal activities in the amygdala. In contrast to pretraining muscimol effects, however, immediate post-training infusions of muscimol into the amygdala failed to affect the acquisition of eyeblink CRs. Together, these findings suggest that neuronal activity in the amygdala during delay eyeblink conditioning is critically involved in mediating fearinduced behaviors (such as USV) and in influencing cerebellardependent conditioned eyeblink responses. Moreover, the formation (or consolidation) of conditioned eyeblink memory in the cerebellum does not require post-training amygdalar activity, as has been reported with other behavioral tasks (McGaugh, 2002).

Aversive tasks, such as eyeblink conditioning, have been proposed to engage two stages related to different aspects of learning (Rescorla and Solomon, 1967; Wagner and Brandon, 1989; Lennartz et al., 1992). During conditioning, animals quickly establish conditioned emotional responses (CERs) in the first stage and then gradually learn the specific motor CR in the second stage. Thus, the nonspecific emotional response emerges faster than the specific motor CR and contributes to the development of the specific motor CR. Two-process models of conditioning predict that if animals do not develop CERs they will learn specific motor CRs slowly (Wagner and Brandon, 1989). Our results support this notion because animals with amygdalar lesions or muscimol infusions did not exhibit the nonspecific fear-induced USV and they required considerably more trials to acquire eyeblink CRs.

Two-process models of conditioning can be applied to eyeblink conditioning by positing that the amygdala is involved in the first process of emotional responses whereas the cerebellum (i.e., interpositus nucleus) is essential for the second process of eyeblink CR acquisition. A considerable body of evidence indicates that the amygdala is a critical structure in emotional learning and expression (Lavond et al., 1993; Davis, 1997; LeDoux, 2000). Studies using rabbits have revealed that animals exhibit conditioned bradycardia (decreased heart rate) responses during the early phase of eyeblink conditioning (Yehle, 1968; Lavond et 
al., 1984). Amygdala lesions have been shown to abolish conditioned bradycardia and reflex facilitation of nictitating membrane responses and retard the learning of eyeblink CR (Weisz et al., 1992; Chachich and Powell, 1998). Conversely, electrical stimulation of amygdalar central nucleus has been found to decrease heart rate and increase nictitating membrane response amplitudes (Whalen and Kapp, 1991). Interestingly, the amygdalar lesion-induced retardation of eyeblink CR learning rate seems more dramatic in rats (the present study) than in rabbits (Weisz et al., 1992). This might reflect species difference in the emotional (fear) state or procedural differences (e.g., eyeblink conditioning in freely moving rats vs restrained rabbits), or both. Regardless, these findings indicate that the amygdala modulates the development of eyeblink CRs by establishing early emotional states.

In eyeblink conditioning, an abundance of evidence indicates that the cerebellum is the essential site of CS-US information convergence and plasticity underlying motor CRs (Thompson, 1986, 1990; Kim and Thompson, 1997; Medina et al., 2002). Lesions of the interpositus nucleus have been found to block eyeblink CRs but not heart rate (fear) conditioning in rabbits (Lavond et al., 1984, 1985). The present results are consistent with previous findings in that interpositus nucleus lesions impair the development of conditioned motor responses without affecting fear responses (Mintz and Wang-Ninio, 2001). In addition, unlike amygdalar lesions, cerebellar lesions do not prevent reflex facilitation in rabbits (Weisz and LoTurco, 1988). Thus, our results in conjunction with other available evidence indicate that the cerebellum is critically involved in motor learning of the second stage but uninvolved in emotional responses of the first stage in two-process models of conditioning.

It is generally accepted that different brain regions subserve multiple memory systems and become engaged in learning about different aspects associated with a given behavioral task (Lavond et al., 1993; Thompson and Kim, 1996; Kim and Baxter, 2001). For example, the cerebellum is essential for motor learning, the amygdala is critical for conditioned fear responses, and the hippocampus is required for spatial and relational memory (Squire and Zola, 1996; Thompson and Kim, 1996; Eichenbaum 2001; Medina et al., 2002); however, these brain regions appear to be involved in modulating other aspects of behavioral tasks. For instance, brain regions other than the cerebellum differentially influence the acquisition of the motor CR even in a simple delay paradigm. Specifically, the amygdala accelerates the acquisition of eyeblink CR by evoking emotional responses, increasing arousal and attention to CS (Gallagher et al., 1990; Weisz et al., 1992). The hippocampus is not required for delay eyeblink CR or fear responses, but nevertheless, hippocampal lesions produce
B

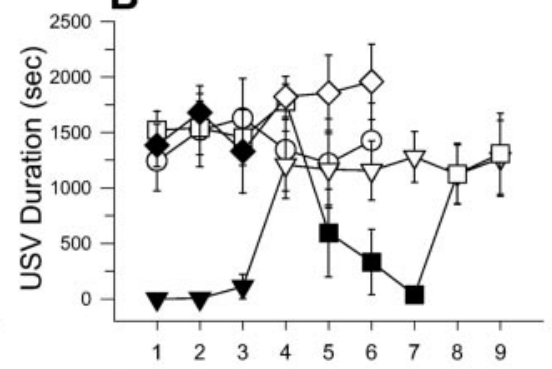

D
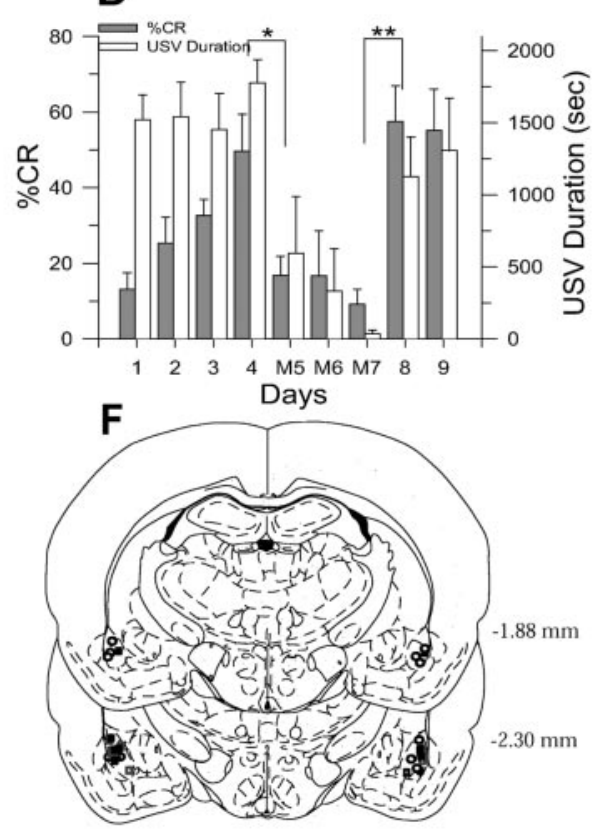

Figure 6. Effects of pretraining, preretention, and immediate post-training muscimol infusions on eyeblink CRs and USVs. $A$, 6 ), and post-training MUSC infusion ( $\diamond, n=5$ ) groups. (Filled symbols denote training sessions with muscimol infusions.) $B$ USV duration recorded during training sessions. C, Comparison of mean CR percentage ( $\pm \mathrm{SE}$ ) displayed by pretraining amplitude to US intensity. F, Location of muscimol infusion sites on the basis of a reconstruction of injection cannula placements in the basolateral amygdalar complex (pretraining MUSC, $\square$; preretention MUSC, $\bigcirc$; post-training MUSC, $\square$ ).

facilitated learning of CR in delay conditioning (Schmaltz and Theios, 1972; Port et al., 1985; Christiansen and Schmajuk, 1992; the present study). The hippocampus is thought to participate in the processing of contextual and temporal information (Hoehler and Thompson, 1980; Good and Honey, 1991; Penick and Solomon, 1991; Kim and Fanselow, 1992; Phillips and LeDoux, 1992; Kim et al., 1995). Thus, it is possible that hippocampal lesion effects on delay eyeblink conditioning (i.e., facilitation) might be attributable to the hippocampus being engaged in processing contextual information that would normally interfere with the formation of CS-US association in the cerebellum (Kim and Baxter, 2001). In support of this, other manipulations that reduced or altered hippocampal functions have also been shown to facilitate acquisition of delay eyeblink conditioning (Berger, 1984; Port et al., 1985; Shors et al., 1992; Chen et al., 1995). Additionally, the hippocampus is necessary for complex eyeblink learning, such as trace conditioning (Moyer et al., 1990; Kim et al., 1995), latent inhibition (Solomon and Moore, 1975), discrimination reversal conditioning (Berger and Orr, 1983), and 


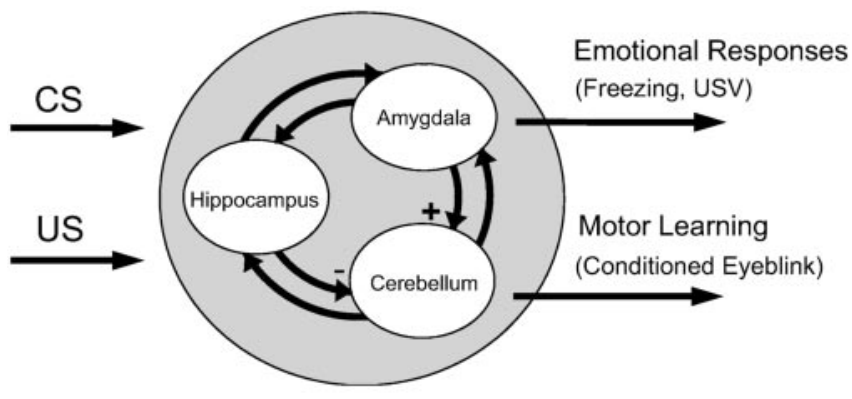

Figure 7. A simple model of neural structures involved in eyeblink conditioning. The amygdala is concerned with emotional responses, which accelerates eyeblink conditioning (+ indicates facilitating effects on the cerebellum). The hippocampus is concerned with processing temporal and contextual information, which can influence eyeblink conditioning ( - denotes inhibitory effects on the cerebellum).

context shift (Penick and Solomon, 1991). The recent studies on trace eyeblink conditioning in glutamate receptor subunit $\delta 2$ mutant mice also emphasizes the role of the hippocampus in eyeblink conditioning (Kishimoto et al., 2001; Takatsuki et al., 2003).

The fact that separate brain regions (e.g., the cerebellum, the amygdala, and the hippocampus) influence different aspects of eyeblink conditioning suggests an interaction between these neural structures. Whalen and Kapp (1991) suggested that amygdala projections to the lateral tegmental field of the brainstem contribute to increased arousal and eyeblink UR amplitudes. The hippocampus can modulate the CS and US inputs via projections to the pontine nucleus and the dorsal accessory olive (Berger et al., 1986; Steinmetz et al., 1988; Schmajuk and DiCarlo, 1992). In addition, the amygdala projects to the hippocampal formation, including a CA1 area, the subiculum, and the entorhinal cortex (Krettek and Price, 1977; Aggleton, 1986). The present findings suggest that the projection from the amygdala to the cerebellum (e.g., via the lateral tegmental field) normally exerts an excitatory influence on the acquisition of eyeblink CRs (Fig. 7). On the contrary, the output from the hippocampus to the cerebellum (e.g., via the pontine nucleus and the dorsal accessory olive) normally exerts an inhibitory influence on eyeblink learning. One prediction from this notion is that combined amygdalar and hippocampal lesions would have compensating effects on the development of eyeblink CRs. We found, however, that combined lesions resulted in slow CR acquisition (similar to the amygdala lesion), suggesting that the amygdala exerts a stronger influence on the cerebellum than the hippocampus in delay eyeblink conditioning (our unpublished data).

In conclusion, the cerebellum, the amygdala, and the hippocampus contribute differentially to delay eyeblink conditioning. The cerebellum is essential to establish the CS-US association for conditioned eyeblink responses but is not necessary for emotional responses. The amygdala contributes to the development of eyeblink CR by eliciting emotional responses. The hippocampus, on the other hand, is not critical for either emotional or eyeblink responses but affects eyeblink CRs perhaps by processing contextual information during conditioning. Thus, even during a simple delay eyeblink conditioning task, animals learn about different aspects associated with the behavioral task, and the overall behavior is a result of interactions between different brain-memory systems.

\section{References}

Aggleton JP (1986) A description of the amygdalo-hippocampal interconnections in the macaque monkey. Exp Brain Res 64:515-526.
Basso MA, Strecker RE, Evinger C (1993) Midbrain 6-hydroxydopamine lesions modulate blink reflex excitability. Exp Brain Res 94:88-96.

Berger TW (1984) Long-term potentiation of hippocampal synaptic transmission affects rate of behavioral learning. Science 224:627-630.

Berger TW, Orr WB (1983) Hippocampectomy selectively disrupts discrimination reversal conditioning of the rabbit nictitating membrane response. Behav Brain Res 8:49-68.

Berger TW, Alger B, Thompson RF (1976) Neuronal substrate of classical conditioning in the hippocampus. Science 192:483-485.

Berger TW, Weikart CL, Bassett JL, Orr WB (1986) Lesions of the retrosplenial cortex produce deficits in reversal learning of the rabbit nictitating membrane response: implications for potential interactions between hippocampal and cerebellar brain systems. Behav Neurosci 100:802-809.

Blanchard DC, Blanchard RJ (1972) Innate and conditioned reactions to threat in rats with amygdaloid lesions. J Comp Physiol Psychol 81:281-290.

Blanchard RJ, Blanchard DC, Agullana R, Weiss SM (1991) Twenty-two $\mathrm{kHz}$ alarm cries to presentation of a predator, by laboratory rats living in visible burrow systems. Physiol Behav 50:967-972.

Brudzynski SM, Bihari F, Ociepa D, Fu XW (1993) Analysis of $22 \mathrm{kHz} u l-$ trasonic vocalization in laboratory rats: long and short calls. Physiol Behav 54:215-221.

Chachich M, Powell DA (1998) Both medial prefrontal and amygdala central nucleus lesions abolish heart rate classical conditioning, but only prefrontal lesions impair reversal of eyeblink differential conditioning. Neurosci Lett 257:151-154.

Chen C, Kano M, Abeliovich A, Chen L, Bao S, Kim JJ, Hashimoto K, Thompson RF, Tonegawa S (1995) Impaired motor coordination correlates with persistent multiple climbing fiber innervation in PKC gamma mutant mice. Cell 83:1233-1242.

Chen L, Bao S, Lockard JM, Kim JK, Thompson RF (1996) Impaired classical eyeblink conditioning in cerebellar-lesioned and Purkinje cell degeneration (pcd) mutant mice. J Neurosci 16:2829-2838.

Choi JS, Brown TH (2003) Central amygdala lesions block ultrasonic vocalization and freezing as conditional but not unconditional responses. J Neurosci 23:8713-8721.

Christiansen BA, Schmajuk NA (1992) Hippocampectomy disrupts the topography of the rat eyeblink response during acquisition and extinction of classical conditioning. Brain Res 595:206-214.

Davis M (1992) The role of the amygdala in fear and anxiety. Annu Rev Neurosci 15:353-375.

Davis M (1997) Neurobiology of fear responses: the role of the amygdala. J Neuropsychiatry Clin Neurosci 9:382-402.

Disterhoft JF, Coulter DA, Alkon DL (1986) Conditioning-specific membrane changes of rabbit hippocampal neurons measured in vitro. Proc Natl Acad Sci USA 83:2733-2737.

Eichenbaum H (2001) The hippocampus and declarative memory: cognitive mechanisms and neural codes. Behav Brain Res 127:199-207.

Fanselow MS, LeDoux JE (1999) Why we think plasticity underlying Pavlovian fear conditioning occurs in the basolateral amygdala. Neuron 23:229-232.

Feldman RS, Meyer J, Quenzer LF (1997) Principles of neuropsychopharmacology. Sunderland, MA: Sinauer.

Gallagher M, Graham PW, Holland PC (1990) The amygdala central nucleus and appetitive Pavlovian conditioning: lesions impair one class of conditioned performance. J Neurosci 10:1906-1911.

Good M, Honey RC (1991) Conditioning and contextual retrieval in hippocampal rats. Behav Neurosci 105:499-509.

Hoehler FK, Thompson RF (1980) Effect of the interstimulus (CS-UCS) interval on hippocampal unit activity during classical conditioning of the nictitating membrane response of the rabbit (Oryctolagus cuniculus). J Comp Physiol Psychol 94:201-215.

Kapp BS, Frysinger RC, Gallagher M, Haselton JR (1979) Amygdala central nucleus lesions: effect on heart rate conditioning in the rabbit. Physiol Behav 23:1109-1117.

Kim JJ, Baxter MG (2001) Multiple brain-memory systems: the whole does not equal the sum of its parts. Trends Neurosci 24:324-330.

Kim JJ, Fanselow MS (1992) Modality-specific retrograde amnesia of fear. Science 256:675-677.

Kim JJ, Thompson RF (1997) Cerebellar circuits and synaptic mechanisms involved in classical eyeblink conditioning. Trends Neurosci 20:177-181. Kim JJ, Rison RA, Fanselow MS (1993) Effects of amygdala, hippocampus, 
and periaqueductal gray lesions on short- and long-term contextual fear. Behav Neurosci 107:1093-1098.

Kim JJ, Clark RE, Thompson RF (1995) Hippocampectomy impairs the memory of recently, but not remotely, acquired trace eyeblink conditioned responses. Behav Neurosci 109:195-203.

Kishimoto Y, Kawahara S, Suzuki M, Mori H, Mishina M, Kirino Y (2001) Classical eyeblink conditioning in glutamate receptor subunit $\delta 2$ mutant mice is impaired in the delay paradigm but not in the trace paradigm. Eur J Neurosci 13:1249-1253.

Konorski J (1967) Integrative activity of the brain. Chicago: University of Chicago.

Krettek JE, Price JL (1977) Projections from the amygdaloid complex and adjacent olfactory structures to the entorhinal cortex and to the subiculum in the rat and cat. J Comp Neurol 172:723-752.

Lavond DG, Lincoln JS, McCormick DA, Thompson RF (1984) Effect of bilateral lesions of the dentate and interpositus cerebellar nuclei on conditioning of heart-rate and nictitating membrane/eyelid responses in the rabbit. Brain Res 305:323-330.

Lavond DG, Hembree TL, Thompson RF (1985) Effect of kainic acid lesions of the cerebellar interpositus nucleus on eyelid conditioning in the rabbit. Brain Res 326:179-182.

Lavond DG, Kim JJ, Thompson RF (1993) Mammalian brain substrates of aversive classical conditioning. Annu Rev Psychol 44:317-342.

LeDoux JE (2000) Emotion circuits in the brain. Annu Rev Neurosci 23:155-184.

Lee HJ, Choi JS, Brown TH, Kim JJ (2001) Amygdalar NMDA receptors are critical for the expression of multiple conditioned fear responses. J Neurosci 21:4116-4124.

Lennartz RC, Weinberger NM (1992) Analysis of response systems in Pavlovian conditioning reveals rapidly versus slowly acquired conditioned responses: support for two factors, implications for behavior and neurobiology. Psychobiology 20:93-119.

McGaugh JL (2002) Memory consolidation and the amygdala: a systems perspective. Trends Neurosci 25:456-461.

Medina JF, Christopher Repa J, Mauk MD, LeDoux JE (2002) Parallels between cerebellum- and amygdala-dependent conditioning. Nat Rev Neurosci 3:122-131.

Mintz M, Wang-Ninio Y (2001) Two-stage theory of conditioning: involvement of the cerebellum and the amygdala. Brain Res 897:150-156.

Miyata M, Kim HT, Hashimoto K, Lee TK, Cho SY, Jiang H, Wu Y, Jun K, Wu D, Kano M, Shin HS (2001) Deficient long-term synaptic depression in the rostral cerebellum correlated with impaired motor learning in phospholipase C beta4 mutant mice. Eur J Neurosci 13:1945-1954.

Moyer Jr JR, Deyo RA, Disterhoft JF (1990) Hippocampectomy disrupts trace eye-blink conditioning in rabbits. Behav Neurosci 1990 104:243-252.

Neufeld M, Mintz M (2001) Involvement of the amygdala in classical conditioning of eyeblink response in the rat. Brain Res 889:112-117.

Paxinos G, Watson C (1997) The rat brain in stereotaxic coordinates, Ed 3. San Diego: Academic.

Penick S, Solomon PR (1991) Hippocampus, context, and conditioning. Behav Neurosci 105:611-617.

Phillips RG, LeDoux JE (1992) Differential contribution of amygdala and hippocampus to cued and contextual fear conditioning. Behav Neurosci 106:274-285.

Port RL, Mikhail AA, Patterson MM (1985) Differential effects of hippocampectomy on classically conditioned rabbit nictitating membrane response related to interstimulus interval. Behav Neurosci 99:200-208.

Raymond JL, Lisberger SG, Mauk MD (1996) The cerebellum: a neuronal learning machine? Science 272:1126-1131.

Rescorla RA, Solomon RL (1967) Two-process learning theory: relation- ships between Pavlovian conditioning and instrumental learning. Psychol Rev 74:151-182.

Schmajuk NA, DiCarlo JJ (1992) Stimulus configuration, classical conditioning, and hippocampal function. Psychol Rev 99:268-305.

Schmaltz LW, Theios J (1972) Acquisition and extinction of a classically conditioned response in hippocampectomized rabbits (Oryctolagus cuniculus). J Comp Physiol Psychol 79:328-333.

Schneiderman N, Fuentes I, Gormezano (1962) Acquisition and extinction of the classically conditioned eyelid response in the albino rabbit. Science 136:650-652.

Shors TJ, Seib TB, Levine S, Thompson RF (1989) Inescapable versus escapable shock modulates long-term potentiation in the rat hippocampus. Science 244:224-226.

Shors TJ, Weiss C, Thompson RF (1992) Stress-induced facilitation of classical conditioning. Science 257:537-539.

Skelton RW (1988) Bilateral cerebellar lesions disrupt conditioned eyelid responses in unrestrained rats. Behav Neurosci 102:586-590.

Solomon PR, Moore JW (1975) Latent inhibition and stimulus generalization of the classically conditioned nictitating membrane response in rabbits (Oryctolagus cuniculus) following dorsal hippocampal ablation. J Comp Physiol Psychol 89:1192-1203.

Squire LR, Zola SM (1996) Structure and function of declarative and nondeclarative memory systems. Proc Natl Acad Sci USA 93:15-22.

Steinmetz JE, Logan CG, Thompson RF (1988) Essential involvement of mossy fibers in projecting the CS to the cerebellum during classical conditioning. In: Cellular mechanisms of conditioning and behavioral plasticity (Woody DA, McGough M, eds), pp 143-148. New York: Plenum.

Takatsuki K, Kawahara S, Kotani S, Fukunaga S, Mori H, Mishina M, Kirino Y (2003) The hippocampus plays an important role in eyeblink conditioning with a short trace interval in glutamate receptor subunit $\delta 2 \mathrm{mu}-$ tant mice. J Neurosci 23:17-22.

Thomas E, Wagner AR (1964) Partial reinforcement of the classically conditioned eyelid response in the rabbit. J Comp Physiol Psychol 58:157-158.

Thompson RF (1986) The neurobiology of learning and memory. Science 233:941-947.

Thompson RF (1990) Neural mechanisms of classical conditioning in mammals. Philos Trans R Soc Lond B Biol Sci 329:161-170.

Thompson RF, Kim JJ (1996) Memory systems in the brain and localization of a memory. Proc Natl Acad Sci USA 93:13438-13444.

Wagner AR, Brandon SE (1989) Evolution of a structured connectionist model of Pavlovian conditioning (AESOP). In: Contemporary learning theories: Pavlovian conditioning and the status of traditional learning theory (Klein SB, Mowrer RR eds), pp 149-190. Hillsdale, NJ: Erlbaum.

Weiss C, Knuttinen MG, Power JM, Patel RI, O'Connor MS, Disterhoft JF (1999) Trace eyeblink conditioning in the freely moving rat: optimizing the conditioning parameters. Behav Neurosci 113:1100-1105.

Weisz DJ, LoTurco JJ (1988) Reflex facilitation of the nictitating membrane response remains after cerebellar lesions. Behav Neurosci 102:203-209.

Weisz DJ, Clark GA, Thompson RF (1984) Increased responsivity of dentate granule cells during nictitating membrane response conditioning in rabbit. Behav Brain Res 12:145-154.

Weisz DJ, Harden DG, Xiang Z (1992) Effects of amygdala lesions on reflex facilitation and conditioned response acquisition during nictitating membrane response conditioning in rabbit. Behav Neurosci 106:262-273.

Whalen PJ, Kapp BS (1991) Contributions of the amygdaloid central nucleus to the modulation of the nictitating membrane reflex in the rabbit. Behav Neurosci 105:141-153.

Yehle AL (1968) Divergences among rabbit response systems during threetone classical discrimination conditioning. J Exp Psychol 77:468-473.

Yeo CH (1991) Cerebellum and classical conditioning of motor responses. Ann NY Acad Sci 627:292-304. 